\title{
COMPARISON OF SALVADORA PERSICA CHEWING STICK AND MANUAL TOOTH BRUSH FOR EFFICACY OF PLAQUE REMOVAL: A RANDOMIZED CONTROLLED TRIAL
}

\author{
Madiha Riasat ${ }^{1}$, Sohaib Hassan², Afaq Farooq ${ }^{3}$, khaula Gul ${ }^{4}$, Kamran Alam $^{5}$, Sofia Shehzad ${ }^{6}$ \\ ${ }^{1}$ Department of Periodontology, KMU-Institute of Dental Sciences, Kohat - Pakistan \\ ${ }^{2}$ Department of Orthodontics, Multan Medical and Dental College, Multan - Pakistan \\ ${ }^{3}$ Department of Periodontology, Sardar Begum dental College, Peshawar - Pakistan \\ ${ }^{4}$ Department of Periodontology Rehman College of Dentistry, Peshawar - Pakistan \\ ${ }^{5}$ Institute of Public Health \& Social Sciences, KMU, Peshawar - Pakistan \\ ${ }^{6}$ Department of Community Dentistry, Sardar Begum Dental College, Peshawar - Pakistan
}

\begin{abstract}
Objectives: To clinically evaluate the efficacy of chewing stick as alternative to tooth brushing for plaque removal in subject with clinically healthy gingival status.

Material and methods: This randomized controlled trial was conducted from March 2020 till December 2020 a total of 80 participants, randomly allocated into two groups of 40 each at Department of Periodontology, Sardar Begum Dental College, Gandhara University, Peshawar, Pakistan. Group A were guided to use toothbrush, while group B was miswak users. Both groups were advised to use the respective group technique twice daily for four weeks. Pre and Post intervention examinations were planned by using Modified Quigley-Hein Plaque Index Quigley-Hein Plaque Index, which measures the plaque levels. Data was recorded on the first day (baseline) and after 4 weeks. Data was analyzed using SPSS v.24.0.
\end{abstract}

Results: Mean age of the study participants was $25.54 \pm 6.004$ years. Plaque was measured using QHPI, at baseline group A presented mean of 5.001 \pm 1.50 , group $B$ had mean of $4.923 \pm 0.63(p=<0.001)$, while after 4 weeks, group A showed mean of 2.52 \pm 7.82 , while mean of group B was 1.37 $\pm 0.427(p=<0.001)$ with more evident decrease in Miswak group.

Conclusion: It was concluded that Salvadora Persica chewing stick was comparatively better anti plaque agent as compared to tooth brushes in this specific study.

Key words: Tooth brush, Miswak, Salvadora Persica, Chewing stick, Dental Plaque Quigley-Hein Plaque Index (QHPI).

This article may be cited as: Riasat M, Hassan S, Farooq A, Gul K, Alam K, Shehzad S. Comparison of Salvadora Persica Chewing Stick and Manual Tooth Brush for efficacy of plaque removal: A Randomized Controlled Trial. J Med Sci 2021 April;29(2):98-101

\section{INTRODUCTION}

Removal of dental plaque is affective in treating gingivitis, and periodontal diseases ${ }^{1}$. Oral health has a highly crucial role for effective healthy life. To forestall oral and dental conditions a good oral cleanliness is required. There are various approaches accessible for the support of oral wellbeing. These are mainly mechanical and chem-

\section{Correspondence}

Dr. Madiha Riasat

Assistant Professor

Department of Periodontology KMU Institute of Dental

Sciences, Kohat - Pakistan

Email: drmadiha.riasat@gmail.com

Cell: +92-346-9202398

Date received: $09-11-2020$

Date revised: 13-01-2021

Date accepted: 11-04-2021 ical methods, among mechanical methods, tooth brushing and chewing stick are widely used ones. Traditional tooth brushing by chewing called Miswak has been used since ancient times ${ }^{2}$. Locally accessibility and a minimal effort to use have established on it the apparatus of decision for plaque control in various networks and is popular among Muslim community. Chewing stick were used by Babylonians some 7000years ago and it is known by different names, it has been called a natural tooth brush and Darkhe-i-Miswak ${ }^{1,3}$. About 182 species of this plant have been utilized as biting sticks all through the world. The most well-known kind of Miswak is a derivative of Salvadora Persica, otherwise called Arak or little tree or bush with a supple stem and root that effectively pulverize between teeth ${ }^{4}$. It is used as a traditional tooth brush for maintenance of oral hygiene. Different studies have reported that 
Comparison Of Salvadora Persica Chewing Stick And Manual Tooth Brush For Efficacy Of Plaque Removal: A Randomized...

the oral health status of chewing stick user are far more better than expected, studies also supports the claim that Miswak sticks are useful for its chemicals content, like it has fluoride, chloride, ascorbic acid, silica, resins, tri-methylamine, and Salvadorine that effectively reduce plaque and gingival inflammation ${ }^{5-7}$. Another study reported that Miswak has significantly removed plaque $(P<0.001)$ from teeth and addressed gingivitis $(\mathrm{P}<0.01)$, when compared with the toothbrush ${ }^{8}$. It has been reported that miswak is as effective as tooth brush. Research claims that removal of plaque using Miswak from inter-proximal site has almost the same effectiveness as plaque removal from any other accessible site. It has been discovered that biting the stick limits plaque collection unnaturally and is effective in prevention of microbial impaction against numerous oral microorganisms ${ }^{9}$.

The international body of World Health Organization(WHO) in 1987, energized the utilization Miswak for oral cleanliness in light of customary accessibility and ease; also it proved that it gives therapeutic effect on gingival disease and is an effective tool for oral hygiene measures ${ }^{2}$. Chewing stick accomplishes the essential basic principal of oral health and could be an appropriate substitute to tooth brush. It is inexpensive and easy accessible in the community, particularly in the developing world. About, 50\% population of Pakistan's society is living in rural area and due to affordable range of chewing stick its purchase is fairly more than tooth brush. Data revealed that affordability of tooth brush is low by $8 \%$ among rural population as compared to urban, which is about $38 \%$ in number. This is the main concern for the selection of salvadora persica sticks compared to manual tooth brush in a country like Pakistan. In a similar way, miswak has been reported to be in daily tool of oral hygiene care and is considered to be practiced in Saudi Arabians (50\%), where about $65 \%$ of population lives in country side, and $43 \%$ of the people living in cities. More over the use of miswak is higher rural population (90\%) in Nigeria and Tanzania, and Karachi ${ }^{10}$.

In order to re-establish the effectiveness of the miswak sticks and proving it as exclusive tool of oral hygiene care in current life style where nylon bristle tooth brush are attractive and easier to use and readily available in every where than the old traditional miswaks. Literature review has proven its importance and benefits at all levels. The present study aimed to evaluate the efficacy of chewing stick against plaque as an adjunct to tooth brush in subjects with clinically healthy gingival status in clinical terms.

\section{MATERIAL AND METHODS}

This Randomized controlled trial was conducted from March 2020 till December 2020 at Department of Periodontology, Sardar Begum Dental College, Gandhara University, Peshawar, Pakistan. Sample size was calculated at $95 \%$ confidence interval and $0.10 \%$ margin of error using WHO calculator11.Sample size was 80 and using simple randomization technique, the samples $(n=40)$ each were allocated into group $A$ (tooth brush users) and group B (miswak users).

After getting the ethical approval, the study included the subjects between the age group of 18-45 years with 20 teeth at least 5 teeth per quadrant that are clinically healthy as per gingival status, subjects showing Basic periodontal examination (BPE), and periodontal depth less than $3 \mathrm{~mm}$. Systemically compromised individuals, pregnant women, lactating mothers, subjects with on going orthodontic treatment for mal-positioned teeth; subjects with carious teeth and overhang margins restorations and subject who were on antibiotics in last 3 months were excluded from the study. All the study subjects were not only given verbal guide lines but also a written document was provided to them; tooth brushing and miswak techniques were demonstrated and guided properly on model followed photographs of different steps to be taken during the whole process.

After taking informed written consent the trial was conducted over 4 weeks duration. Group A used tooth brush with tooth paste provided by the researcher and the participants were directed to brush twice a day: after breakfast and after dinner for about four weeks. In group $B$, miswak was used with the same frequency of twice daily and at the same times for four weeks. At the baselines, BPE was carried out to access the periodontal status(calculus, periodontal pocket, bleeding gum) of the participants by Community Periodontal Index (CPI). Plaque scores were recorded both at baseline and at follow up after four weeks. Identification of plaque was done using dental plaque-disclosing tablets containing 1.36\% Erythrosine (Produits Dentaires SA Vevey. Swizerland) while scoring was done using modified Quigley Hein Plaque Index (QHPI), the tool was used to measure different plaque levels at buccal and lingual aspect per tooth 10. The same procedure was repeated after 4 weeks to record the follow-up results. SPSS v.24.0 used for data analysis. The paired t-test was used to determine the difference among means of two different groups, where $p$-value $\leq 0.05$ was taken as significant. Whole mouth $=$ total score $/$ number of surface examined Plaque was graded as Quigley Hein 
Comparison Of Salvadora Persica Chewing Stick And Manual Tooth Brush For Efficacy Of Plaque Removal: A Randomized...

Index, a score of 0 to 5 wa s assigned to each facial and lingual surface.

\section{RESULTS}

The mean age of the sample was $25.54 \pm 6.004$ years, while distribution as per age group with gender is given in table I. The study tested the hypothesis for difference in means of Quigley Hein Plaque Index (QHPI) for both groups at two different intervals, results revealed a significant difference $(p$-value $=<0.001)$ at both intervals with better results for Miswak group as shown in table II.

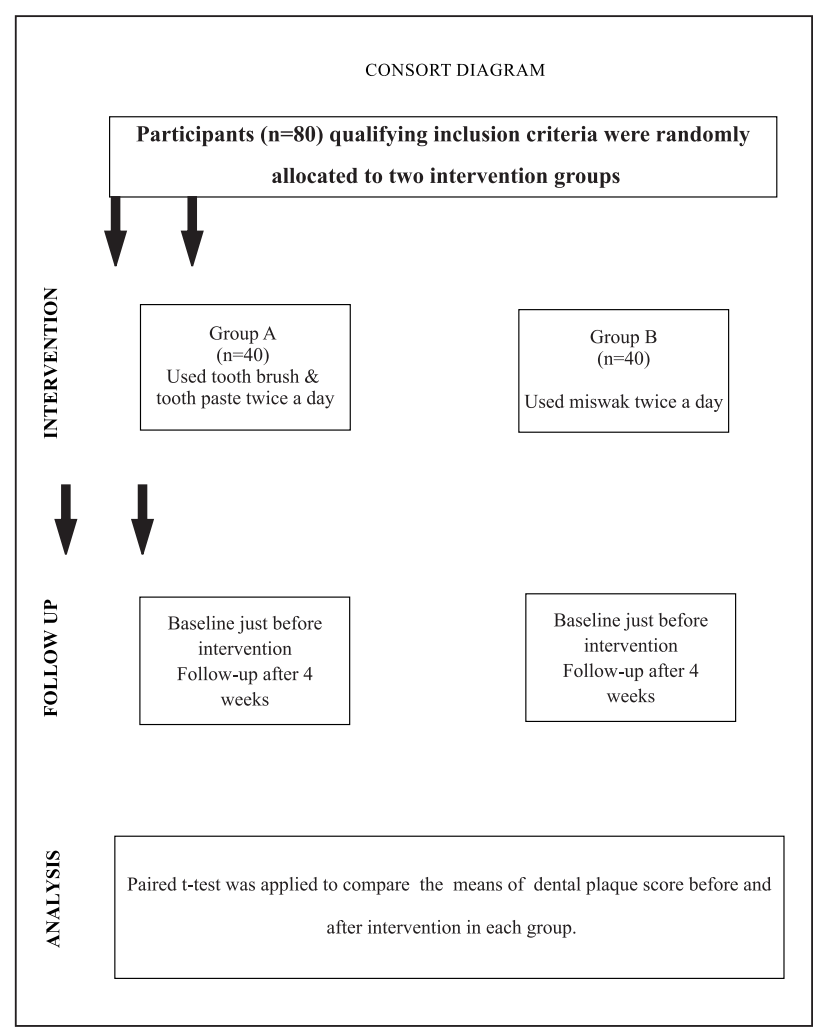

Fig 1: Flow chart of the study according to CONSORT guidelines

The Plaque Index System

\begin{tabular}{|c|c|}
\hline Scores & Criteria \\
\hline 0 & No plaque \\
\hline 1 & $\begin{array}{c}\text { Separate flecks of plaque at the cervical margin of } \\
\text { the tooth }\end{array}$ \\
\hline 2 & $\begin{array}{c}\text { A thin continuous band of plaque (up to one } \mathrm{mm} \text { ) at } \\
\text { the cervical margin of the tooth }\end{array}$ \\
\hline 3 & $\begin{array}{c}\text { A band of plaque wider than one mm but covering } \\
\text { less than one-third of the crown of the tooth }\end{array}$ \\
\hline 4 & $\begin{array}{c}\text { Plaque covering at least one-third but less than two- } \\
\text { thirds of the crown of the tooth }\end{array}$ \\
\hline 5 & $\begin{array}{c}\text { Plaque covering two-thirds or more of the crown of } \\
\text { the tooth }\end{array}$ \\
\hline
\end{tabular}

J Med Sci 2021 April;29(2):100-101
Table 1: Age group for the study population

\begin{tabular}{|c|c|c|c|}
\hline Age Groups (Years) & Male (\%) & Female (\%) & Total (\%) \\
\hline $18-27$ & $11(13.75)$ & $04(5)$ & $15(18.75)$ \\
\hline $28-37$ & $35(43.75)$ & $18(22.5)$ & $53(67.5)$ \\
\hline $38-45$ & $10(12.5)$ & $02(2.5)$ & $12(15)$ \\
\hline
\end{tabular}

Table 2: comparison among both groups based on modified quigley hein plaque index (QHPI)

\begin{tabular}{|c|c|c|c|}
\hline Time & Group & Mean \pm SD & P-value \\
\hline Baseline & Tooth Brush & $1.50 \pm 5.001$ & \multirow{2}{*}{$<0.001$} \\
\cline { 2 - 3 } & Miswak & $0.63 \pm 4.923$ & \\
\hline \multirow{2}{*}{$\begin{array}{c}\text { After 4 weeks of } \\
\text { intervention }\end{array}$} & Tooth brush & $7.82 \pm 2.52$ & \multirow{2}{*}{$<0.001$} \\
\cline { 2 - 3 } & Miswak & $0.427 \pm 1.37$ & \multicolumn{1}{|c}{} \\
\hline
\end{tabular}

\section{DISCUSSION}

Plaque is well known multi-factorial entity with in vivo malfunctioning. Microorganism of plaque S. Sanguis is the primary colonizer in the oral cavity, and is placed in the deeper layer of plaque, therefore dentifrices may not be able to stop its colonization. In comparison to our study results, Poure slami, et al. have reported that the minimum concentration of Salvadora Persica miswak stick required for effectively killing of $\mathrm{S}$. Sanguis microorganisms the concentration was only $7.4 \mathrm{mg} / \mathrm{ml}$; this proved effectiveness of miswak against S. Sanguis ${ }^{12}$. Increased efficacy of miswak may be due to several reasons: traces of Salvadora Persica $10 \mathrm{mg} / 10 \mathrm{ml}$ solution were detected in the mouth up to 6 hours after use expectoration this substantively in approximate, but it gives a well-defined and comparable picture. Moreover, Miswak is generally used for longer period than tooth brush, cleaning usually done 5-10 minutes each time and the plant fibers remove the plaque along with massage to the gum3.

The reason of choosing the salvadora persica tree chewing stick was based on a number of factors. Miswak is commonly used in Pakistan, Indian sub continents and middle-east region. It is inexpensive with acceptable taste and has anti plaque and medicinal properties ${ }^{13,14}$. The use of tooth paste with brush could be the reason of significant reduction of plaque in tooth brush group; other studies used tooth brush alone in comparison with chewing stick ${ }^{15,16}$. In the current clinical trial, participants of the study were observed over a period of 4 weeks. This decision was based on the fact that previous studies have shown that after 9 to 21 days without proper oral hygiene, healthy gingiva develops heavy accumulation of plaque and leads to generalize mild gingivitis ${ }^{17}$. This study was designed to be a convenient model for detection of plaque inhibitory 
ability of the chewing stick and to determine its relative activity in relation to the well-established tooth brush. Similar study designs were utilized in different studies worldwide and almost similar results were obtained, which showed better results for Miswak ${ }^{11-18}$. Quigley Hein plaque index was chosen in this study to measure the plaque score because it is the most commonly utilized index in previous similar investigations, which is a visual determination of disclosed plaque on cervical $1 / 3$ rd of tooth surface. Plaque disclosing agents are available in the form of chewable tablets, lozenges gums, and rinses and contain 1.36\% erythrosine. Many studies are being directed to know the anti-microbial activities of the Miswak, results revealed excellent effect of Miswak killing the microorganisms ${ }^{19}$.

\section{CONCLUSION}

It was concluded that Salvadora Persica chewing stick remains a good anti plaque agent as compared to tooth brush users. In order to maintained oral health and preventing dental diseases, routine use of chewing stick is a better and good alternate to tooth brush.

\section{REFERENCES}

1. Wu CD, Darout IA, Skaug N. Chewing sticks: timeless natural toothbrushes for oral cleansing. J Periodontal Res 2001;36(5):275-84.DOI: 10.1034/j.16000765.2001.360502.x.

2. Haque MM, Alsareii SA. A review of the therapeutic effects of using miswak (Salvadora Persica) on oral health. Saudi Med J 2015;36(5):530-43.DOI: 10.15537/ smj.2015.5.10785.

3. Niazi F, Naseem M, Khurshid Z, Zafar MS, Almas K. Role of Salvadora persica chewing stick (miswak): A natural toothbrush for holistic oral health. Eur J Dent 2016;10(2):301-8.DOI: 10.4103/1305-7456.178297.

4. Almas AK, Almas K. Miswak (salvadora persica chewing stick) and its role in oral health; an update. JPDA 2013;22(04):255.

5. Patel PV, Shruthi S, Kumar S. Clinical effect of miswak as an adjunct to tooth brushing on gingivitis. J Indian Soc Periodontol 2012;16(1):84-8.DOI: 10.4103/0972124X.94611

6. Darout IA, Skaug N, Albandar JM. Subgingival microbiota levels and their associations with periodontal status at the sampled sites in an adult Sudanese population using miswak or toothbrush regularly.Acta Odontol Scand 2003;61(2):115-22. DOI: 10.1080/00016350310002784.

7. Al-Sabawi N, Al Sheikh Abdal A, Taha MY. The antimicrobial activity of Salvadora persica solution (miswak-siwak) as root canal irrigant (a comparative study). Univ Sharjah J Pure Appl Sci 2007;4(3):69-91.

8. Al-Otaibi M, Zimmerman M, Angmar-Månsson B. Prevailing oral hygiene practices among urban Saudi Arabians in relation to age, gender and socio-economic background. Acta Odontol Scand 2003;61(4):212-6. DOI: 10.1080/00016350310004070.
9. 9. Sukkarwalla A, Ali SM, Lundberg P, Tanwir F. Efficacy of miswak on oral pathogens. Dent Res J (Isfahan) 2013;10(3):314-20.DOI: 10.4103/1735-3327.115138.

10. 10. Quigley GA, Hein JW. Comparative cleansing efficiency of manual and power brushing. J Am Dent Assoc (1939) 1962;65:26-9.DOI: 10.14219/jada.archive.1962.0184.

11. 11. Patel PV, Shruthi S, Kumar S. Clinical linical effect of miswak and adjunct to tooth brushing on gingivitis.J Indian Soc Periodontol2012:16(1):84-88.DOI: 10.4103/0972$124 X .94611$.

12. Dahiya P, Kamal R, Luthra RP, Mishra R, Saini G. Miswak: A periodontist's perspective. J Ayurveda Integr Med 2012;3(4):184-7.DOI: 10.4103/0975-9476.104431.

13. Haque MM, Alsareii SA. A review of the therapeutic effects of using miswak (Salvadora Persica) on oral health. Saudi Med J 2015;36(5):530-43.DOI: 10.15537/ smj.2015.5.10785.

14. Malik AS, Shaukat MS, Qureshi AA, Abdur R. Comparative effectiveness of chewing stick and toothbrush: a randomized clinical trial.N Am J Med Sci 2014 Jul;6(7):3337. DOI: $10.4103 / 1947-2714.136916$

15. Sukkarwalla A, Ali SM, Lundberg P, Tanwir F. Efficacy of miswak on oral pathogens.Dent Res J (Isfahan). 2013 May;10(3):314-20. DOI: 10.4103/1735-3327.115138

16. Nordin A, Bin Saim A, Ramli R, Abdul Hamid A, Mohd Nasri NW, Bt Hj Idrus R. Miswak and oral health: An evidence-based review. Saudi J biolog sci 2020;27(7):180110.DOI.org/10.1016/j.sjbs.2020.05.020

17. Al-Otaibi M, Al-Harthy M, Soder B, Gustafsson A, Angmar-Mansson B. Comparative effect of chewing sticks and toothbrushing on plaque removal and gingival health. Oral Health Prev Dent 2003;1(4):301-7.

18. Niazi F, Naseem M, Khurshid Z, Zafar MS, Almas K. Role of Salvadora persica chewing stick (miswak): A natural toothbrush for holistic oral health. Eur J Dent 2016;10(2):301-8.DOI: 10.4103/1305-7456.178297.

CONFLICT OF INTEREST: Authors declare no conflict of interest

GRANT SUPPORT AND FINANCIAL DISCLOSURE: NIL

\section{AUTHOR'S CONTRIBUTION}

Following authors have made substantial contributions to the manuscript as under

Riasat M: Study idea, concept, design and drafting.

Hassan S: Study supervision and critical revision.

Farooq A: Data collection.

Gul K: Statistical Analysis.

Alam K:

Proof reading.

Shehzad S: Data Collection.

Authors agree to be accountable for all aspects of the work in ensuring that questions related to the accuracy or integrity of any part of the work are appropriately investigated and resolved. 